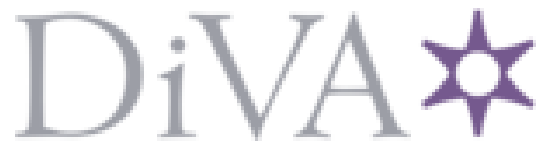

http://www.diva-portal.org

\title{
Postprint
}

This is the accepted version of a paper published in Advances in Quantum Chemistry. This paper has been peer-reviewed but does not include the final publisher proof-corrections or journal pagination.

Citation for the original published paper (version of record):

Linderberg, J., Brändas, E., Öhrn, Y., Sabin, J. (2017)

Per-Olov Löwdin.

Advances in Quantum Chemistry, 74: 1-7

https://doi.org/10.1016/bs.aiq.2016.04.001

Access to the published version may require subscription.

N.B. When citing this work, cite the original published paper.

Permanent link to this version:

http://urn.kb.se/resolve?urn=urn:nbn:se:uu:diva-337590 


\section{Per-Olov Löwdin}

\section{Jan Linderberg ${ }^{a}$, Yngve Öhrn ${ }^{b}$, Erkki J. Brändas ${ }^{c}$, and John R. Sabin ${ }^{\text {b,d }}$}

${ }^{a}$ Chemistry Department, Aarhus University, Aarhus, Denmark

${ }^{\mathrm{b}}$ Quantum Theory Project, University of Florida, Gainesville, FL, USA

${ }^{\mathrm{c}}$ Chemistry Department, Uppsala University, Uppsala, Sweden

${ }^{\mathrm{d}}$ Department of Fysik, Kemi, og Farmaci, University of Southern Denmark, Odense, Denmark

This volume celebrates the centennial of the birth of one of the major figures in the world of quantum chemistry, Per-Olov Löwdin. As one of the founders of the science of quantum chemistry he contributed more than sixty years to the field. His many varied scientific accomplishments include the introduction of novel basic concepts, which are today inherent parts of the development of theoretical chemical physics and quantum chemistry. He advocated and developed linear algebra, partitioning technique, orthogonalization procedures, and established basic notions such as correlation energy, natural spin orbitals, general configuration interaction (CI) methods, reduced density matrices and he pioneered interesting applications to neighboring fields such as quantum biology.

$\mathrm{He}$ contributed to the sociology and the international spread of quantum chemistry through Summer Schools in the Scandinavian Mountains, Winter Institutes at the Sanibel Island in the Gulf of Mexico; all known for their mix of intense lectures schedules, adventurous mountain hikes, hard-fought soccer and water polo games. He established the Quantum Chemistry Institute at Uppsala University, and the Quantum Theory Project, (QTP) at the University of Florida at Gainesville. Both have for many years been influential research centers for the study of novel molecular and material systems.

Uppsala and Gainesville were the nodal points in Per-Olov Löwdin's World Wide Web of quantum chemistry. He was a scientist, who acknowledged the importance of a deductive approach to science and introduced new and lasting education and wisdom through schooling and lecturing, while maintaining an unusual zeal in spreading the good word due to extensive travel and indefatigable concern about teaching quantum chemistry through allembracing lecture tours. He took new initiatives for making scientists from Latin America, Africa, and Asia members of his community.

Löwdin was born in Uppsala on October 28, 1916 as the son of the musician Erik Wilhelm Löwdin and his wife Eva Kristina, nee Östgren. He showed early mathematical proficiency in his schoolwork, and when he entered Uppsala University in 1935, his plans were to major in mathematical physics. His first scientific paper in 1939, on the Lorentz- 
transformation and the kinematical principle of relativity, was published in Swedish in the journal Elementa. The years of war that followed meant interruptions in communications and research opportunities and Löwdin, like most young Swedish men, spent time in the military, defending his country.

The new quantum electrodynamics presented serious challenges to a theoretician and Löwdin's research notes from the 1940's on this topic show that he spent much time and effort working on these problems. An extended stay with Wolfgang Pauli at Zurich in 1946 became a turning point in Löwdin's scientific interests. At about this time, he started work in solid-state physics and began his dissertation research with Professor Ivar Waller at Uppsala. The topic of his thesis work was a quantum mechanical study of ionic crystals and the examination of the Cauchy relations. These relations arise from the assumption of pair-wise interactions between spherical ions, but were not satisfied in real crystals such as sodium chloride. This pioneering application of quantum mechanics, before the advent of electronic computers, was accomplished with the aid of a cadre of doctoral students using desk calculators and ingenious numerical algorithms designed by Löwdin.

A Theoretical Investigation into Some Properties of Ionic Crystals. A Quantum Mechanical Treatment of the Cohesive energy, the Interionic Distance, the Elastic Constants, and the Compression at High Pressures with Numerical Applications to some Alkali Halides. (Almqvist \& Wiksell, Uppsala, 1948) is the full title of Löwdin's dissertation for the degree of Doctor of Philosophy. The preface is marked May 1, 1948, the successful defense took place some three weeks later, and the ring, laurel, and diploma, the Swedish insignia of the doctorate, were awarded at the commencement ceremony on May 31.

It is interesting to read Löwdin's discussion of his method of investigation and the numerical results from Chapter XI. He specifies the fixed nuclei Hamiltonian in the Schrödinger form where no relativistic effects are considered. He specifies the oneelectron approximation with the free ion orbitals and shows that polarization and van der Waals effects are small compared to the terms from exchange and the S-energy. This latter concept was to remain a key feature in Löwdin's future work. He considered all overlap integrals, denoted $S_{\mu \nu}$ and chose to evaluate the formal energy expression to second order. Only nearest neighbor overlap was included since he found the others to be smaller than the general tolerance level he adopted. The detailed numerical calculations were based on the so-called $\alpha$-function expansions. Orbitals on one atomic center were expanded in terms of spherical harmonics on a neighboring center. The resulting radial factors are the Löwdin $\alpha$-functions. 
The failure of the Cauchy relations derives from the three- and four-body interactions, which stem from the overlap terms. The description of the properties of ionic crystals was brought to a new and improved level by Löwdin's thesis and he developed an arsenal of tools, which were sharpened and extended, throughout his career.

A five month stay with Neville Mott at Bristol in 1948, and extended periods with Robert Mulliken at Chicago, and with the group of Hertha Sponer at Duke University in the early 1950 's set the tone for life filled with international travel. Particularly significant was a stay with the Solid State and Molecular Theory Group of John C. Slater at the Massachusetts Institute of Technology. There developed a close association between Slater and Löwdin, which was to last until Slater's death in 1976.

Ram's Head Inn on Shelter Island, in Gardiners Bay at the Eastern end of Long Island, was the venue for a conference that was considered epoch-making for the emerging field of quantum chemistry by the participants. The National Academy of Sciences sponsored the Conference on Quantum-Mechanical Methods in Valence Theory with financial support of the Office of Naval Research.

It was held September 8 to 10,1951, and was attended by the leading figures in the field [1]. Emphasis was given to numerical work. Slater and Ufford reported on the use of electronic computers for self-consistent field calculations, Coulson and Barnett were implementing the $\zeta$-function technique in London, Roothaan, Ruedenberg, and Shull at Chicago and Ames were pursuing diatomic integrals, Kotani's table project was well under way, and Löwdin could present experiences with direct numerical integration methods, which he was developing together with Stig Lundqvist. Per-Olov Löwdin was now an established scientist in the new field of quantum chemistry and he came to play a decisive role in forming the program for quantum chemistry in the post-war world.

Three publications are particularly noteworthy in defining the scientist Per-Olov Löwdin in the first half of the 1950's. His concern with overlap led him to formulate symmetric orthogonalization as a means of forming an orthonormal basis from an overlapping one [2]. This paper may still be among his most cited works [3] and has been an essential element in the justification of neglect of differential overlap [4]. The trilogy Quantum Theory of Many-Particle Systems [5] was worked out during Löwdin's stay with Slater's group, and contains a detailed analysis of the configuration space method for dealing with the correlation problem. Density matrices were used as the principle vehicle for the advancement of interpretation of many-electron wave functions. Detailed prescriptions were offered for the evaluation of density matrices from general 
wave functions in the form of superposition of configurations. General orbital basis sets with overlaps were used. The natural spin orbitals were defined and the first efforts to formulate extended Hartree-Fock methods appeared here. Löwdin also initiated the use of projection operators in order to handle degenerate states. Spin multiplets were of primary concern and the foundation was laid for the later development of the alternant molecular orbital approach [6]. Quantum Theory of Cohesive Properties of Solids [7] exhibits, in its 172 pages, the structure of the theoretical approach towards the description of electronic properties of matter as Löwdin saw it at the time. The numerical procedures, density matrices, natural orbitals, and projection operators were developed in these papers and a thorough review of the literature was included.

Löwdin received substantial grants that enabled the creation of the Quantum Chemistry Group at Uppsala University in 1955. The King Gustaf VI Adolf's 70-years Fund for Swedish Culture and the Knut and Alice Wallenberg's Foundation provided funding for the project, while Löwdin's position as research professor was supported by the Swedish Natural Sciences Research Council. Jointly with Inga Fischer-Hjalmars, Löwdin arranged the first symposium on quantum chemistry in Sweden at Uppsala and Stockholm in 1955 with participation from the leading experts [8].

Extension of the group was made possible by a research grant starting in 1957 from Aerospace Research Laboratories, OAR, through the European Office of Aerospace Research $(O A R)$, United States Air Force. An agreement with the Swedish agencies opened the possibility for purchasing a state-of-the-art electronic computer, the ALWAC IIIE. This was the first device of its kind at Uppsala, and was formally inaugurated in conjunction with the group's new offices at Rundelsgränd on April 23, 1958, the centennial of the birth of Max Planck.

The electronic correlation problem was a primary research theme in the Quantum Chemistry Group when Jan Linderberg and Yngve Öhrn joined the group in 1957 and 1958 respectively. The review [9] and Yoshizumi's bibliography [10] had been submitted, natural orbitals had been determined [11] and the Quantum Chemistry Group was emerging as a center for quantum chemical investigation. Further enhancement came through the Summer Schools. Vålådalen in the mountains of Sweden, was the location for the first Summer School, held in August 1958. Löwdin managed to gather several prominent lecturers such as Robert Mulliken, Linus Pauling, Kenneth Hedberg, F.A. Matsen and others for the final symposium week. Ruben Pauncz, a participant then, returned as a valued lecturer for more than twenty years in these annual Summer Schools.

Quantum Chemistry became recognized as an academic discipline in its own right at 
Uppsala University with the establishment of a chair in the subject. Löwdin was appointed to the chair in 1960, the same year that he founded an interdisciplinary research institute, the Quantum Theory Project for Research in Atomic, Molecular, and Solid-State Theory (informally known as QTP)), at the University of Florida. Dean Linton E. Grinter and the heads of the departments of chemistry and physics at UF, Professor Harry S. Sisler and Professor Stanley S. Ballard, respectively, provided the local support for Löwdin and a small contingent of young Swedish scientists [11] as the original staff of the new QTP. With academic homes on both sides of the Atlantic the number of quantum chemists connected to Löwdin grew and was sustained by the Scandinavian Summer Schools and Florida Winter Schools in Quantum Chemistry. It is estimated that about 4,000 scientists have attended a summer school, winter institute, or conference organized by Löwdin and his colleagues.

There were certain areas of theory that were not embraced by Löwdin in the early years. Group theory was not given a satisfactory form to his liking until John Coleman had lectured on group algebra and Löwdin could cast this in the form of linear algebra [12]. Second quantization had been familiar to him since the 1940's when he worked with quantum electrodynamics and he wanted to connect the use of the Fock space in many-electron theories with the configuration space formulation. In spite of asking his junior colleagues to study the early papers of V. Fock, and others on the subject, no concrete project arose from these efforts and Löwdin seemed to share Slater's feelings [13] that field operators were of little use in the study of electronic systems. It was the influence of Stig Lundqvist that inspired the use of field theoretical methods in the Uppsala and Florida groups.

In 1964 POL started the series Advances in Quantum Chemistry and later, in 1967, he founded the Wiley academic journal the International Journal of Quantum Chemistry. In its first issue he presented the program and outlined in detail the nature of the new field [15].

Through 1960, Löwdin had authored and coauthored some fifty papers. He added more than two hundred in the following forty years. These covered topics in quantum genetics, proton tunneling, and science in society in addition to further pursuits in quantum theory. The series Studies in Perturbation Theory I-XIV demonstrated a search for economy and elegance in presentation, which was important to Löwdin and became one of his trademarks as a scientist. Löwdin frequently referred to "the economy of thinking" as shorthand for elegance and compactness of a mathematical derivation. This characteristic manifests itself in his book Linear Algebra for Quantum Theory (J. Wiley \& Sons, New York 1998), which summarizes over five decades of Löwdin's teaching efforts. Even after his official retirement from the University of Florida faculty in 1992, he and his wife Karin 
continued to travel between Uppsala and Gainesville. Their Florida stays coincided with the annual Sanibel Symposia, where Löwdin always attended all sessions, and from his first row seat continued his habit of making insightful and often complimentary remarks after many of the plenary presentations.

Uppsala University bestows a Jubilee doctorate on those alumni who have survived fifty years after their doctoral commencement. Thus it was that Löwdin received a new laurel and an additional diploma on May 29, 1998, as well as a two shot salute by the artillery cannon outside the university aula. The president of the student union saluted the five recipients with a speech that was answered by Löwdin in his characteristically youthful style. Five months later he had a serious heart operation. He never recovered fully. His health deteriorated, and he passed away quietly on October 6, 2000. A memorial symposium was arranged at Uppsala on the day before the funeral, on October 26. Many of Löwdin's colleagues and friends also gathered on the University of Florida campus to honor his memory with eulogies by Löwdin's longtime collaborator and friend Harrison Shull, and by Robert A. Bryan, who held many top administrative positions at UF, including that of President, during most of Löwdin's tenure at Florida. The 42'nd Sanibel Symposium held in 2002 was dedicated to his memory.

We remember Löwdin as a teacher, an indefatigable lecturer, a helpful colleague, and a friendly competitor. Perhaps his most important characteristic is that of a true internationalist. The Scandinavian Summer Schools, the Florida Winter Schools, and the Sanibel Symposia have, through the vision of Per-Olov Löwdin, furthered international cooperation and friendship between scientists from all continents. He was quoting Harrison Shull, [16], "a veritable giant in the scientific Universe, a dynamo of energy, full of joie de vivre and a kind mentor to us all". Per-Olov, or Pelle as he wanted to be called, was the most colourful, exciting and fascinating person, always maintaining that we all worked in quantum chemistry “JUST FOR FUN"!

It should be noted that much of the text in this chapter is taken with permission from: $\mathrm{J}$. Linderberg, N.Y. Öhrn, and J.R. Sabin, Adv. Quantum Chem. 41 (2002) xi. 


\section{REFERENCES}

1. R.G. Parr and B. L. Crawford, Jr., Proc. Nat. Acad. Sci. 38 (1952) 547.

2. P.O. Löwdin, J. Chem. Phys. 18 (1950) 365.

3. R. Manne in Quantum Science. Methods and Structure (Plenum Press, New York 1976 ) Eds. J.-L. Calais, O. Goscinski, J. Linderberg, and N. Y. Öhrn, p. 25.

4. R.G. Parr, The Quantum Theory of Molecular Electronic Structure

(W.A.Benjamin, Inc. 1963) p. 51; and J. Chem. Phys. 33 (1960) 1184.

5. P.O. Löwdin, Phys. Rev. 97 (1955), 1474, 1490, 1509.

6. J.-L. Calais, Abstracts of Uppsala Dissertations in Science 52 (1965), R. Pauncz, Alternant Molecular Orbital Method (W.B. Saunders, Philadelphia 1967)

7. P.O. Löwdin, Adv. Phys. 5 (1956) 1.

8. I. Fischer-Hjalmars and P.O. Löwdin, Sv. Kem. Tidskrift 67 (1955) 365.

9. P.O. Löwdin, Adv. Chem. Phys. 2 (1959), 207.

10. H. Yoshizumi, Adv. Chem. Phys. 2 (1959) 323.

11. P.O. Löwdin, in Partners in Progress (Eds. A. Kastrup, N. W. Olsson, Swedish Council of America, 1977) p. 255.

12. P.O. Löwdin, Rev. Mod. Phys. 39 (1967), 259.

14. J.C. Slater, Am. J. Phys. 36 (1968), 69.1

15. P. O. Löwdin, Int. J. Quant. Chem. 1 (1967), 1.

16. H. Shull, in Fundamental World of Quantum Chemistry (Eds: E. J.Brändas, E. S. Kryachko, Kluwer Academic Publishers, 2003) p. 1. 